\title{
VIEWPOINT Profitability versus environmental performance: Are they competing?
}

\author{
David Muth
}

$\mathrm{T}$

here is a common perception that environmentally sustainable management practices are competitive with profitability in primary Corn Belt production systems. Sustainable conservation practices in many cases (1) utilize land resources that could be producing commodities and (2) require financial inputs often with limited direct financial returns (USDA NRCS 2014a; Pannell et al. 2006). Furthermore, land tenure dynamics and high costs of production often make near-term financial returns the critical decision point for today's independent farming businesses. These characteristics of our current production systems can lead to conflict between environmental and financial performance. However, we believe that emerging precision agriculture technologies, specifically the ability to make decisions and implement management practices at a smaller spatial scale, provide opportunities for simultaneously improving environmental and financial performance of primary Corn Belt production systems. The first step toward this goal is understanding how subfield variability impacts both environmental and economic performance. The following discussion uses a case study example to show how emerging precision data are helping us quantify subfield variability in our systems. The example is then used to quantify environmental and financial performance at a $10 \mathrm{~m}(33 \mathrm{ft})$ resolution scale for the field. The results demonstrate how focusing on increased profitability, and more specifically on return on investment (ROI), can be one of our most powerful tools for improving sustainability. The discussion then presents a vision for future agronomic management concepts that simultaneously increase profit and deliver sustainable environmental performance.

\section{SUBFIELD VARIABILITY AND ENVIRONMENTAL PERFORMANCE}

Technology developments over the past two decades have created equipment and

David Muth is the senior vice president of analytics at AgSolver, Inc., Ames, lowa. data management tools that provide large amounts of high-resolution data describing our row crop productions systems. Institutions across the agribusiness supply chain, including academic, government, small, and large businesses, are working to build value-added outcomes from the rich datasets that are available. The precision datasets are making variable rate soil fertility management and seeding more common practices (Ebel and Schimmelpfennig 2011). One of the most important outcomes from the emerging high-resolution precision data is understanding subfield variability, and more specifically, how that variability impacts performance of the agronomic system. Land managers intuitively understand the variability within individual fields based on their interactions. It is currently difficult for them to make decisions that account for, and potentially take advantage of, subfield variability. Because of this, an important role of high-resolution precision data is quantifying the extent of subfield variability and describing how that variability impacts financial and environmental performance.

Figure 1 shows a 56 ha $(138$ ac) field from north central Iowa. The field in figure 1 has more diverse characteristics than many Corn Belt fields, but it demonstrates our general understanding that between $5 \%$ and $15 \%$ of fields consistently face productivity challenges. This field is comprised of multiple soil types (USDA NRCS 2014b) that range in organic matter from $1.5 \%$ to $7.5 \%$ in the top horizon of each soil (figure 1a). The field is generally flat with slopes below 3\% (figure 1b), but there is a ridge comprised of high sand fraction $(>80 \%)$ soils (figure $1 c$ ) that runs through the western part of the field with slopes exceeding 5\%. Figure $1 \mathrm{~d}$ shows the average yield in this field from the harvest yield monitor over three years-from 2008 to 2010. There are consistent yield impacts from the lighter, higher slope soils in this field. The northeast corner of this field is comprised of soils with properties that suggest strong productivity poten-
tial-Corn Suitability Rating 2 ranging from 88 to 90 . However, this corner of the field has consistent negative yield impacts from drainage and soil moisture issues. The subfield variability in this field is well understood and predictable. The challenge, however, has been to effectively make agronomic and business decisions that maximize financial and environmental performance of the field, accounting for the known variability.

Muth et al. (2012) used USDA Natural Resources Conservation Service conservation planning metrics employed at a subfield scale to evaluate environmental performance of the field (figure 1) under management practices that included a residue harvest strategy. An important outcome of this work was creating a methodology to quantify environmental performance at a scale that accounts for variability across the field. Figure 2a shows the outcomes of this analysis. Areas of the field where soil organic matter would be decreasing (i.e., soil conditioning index < $0)$ and where soil erosion was above tolerable levels (i.e., erosion > tolerable soil loss level) were identified.

Simultaneously increasing environmental and financial performance in a field requires understanding more than the conservation planning metrics shown in figure 2a. Nutrient use efficiency is a critical metric for improving water quality, greenhouse gas impacts, and profitability. Many fields, including the one shown in figure 1 , employ fertility management plans that apply nutrients uniformly across the field. When nutrients are managed uniformly and we encounter the yield variability seen in figure $1 \mathrm{~d}$, it is clear that different areas of the field are less effective at turning applied nutrients into commodity production. Coupling precision data with simulation tools can help us identify where nutrient loss factors are high. Figure $2 \mathrm{~b}$ shows simulated nitrate $\left(\mathrm{NO}_{3}\right)$ leaching levels using the DeNitrification-DeComposition biogeochemistry model calibrated to yields and soil characteristics at a $10 \mathrm{~m}$ (33 ft) scale (Giltrap et al. 2010). Nitrate losses are gen- 


\section{Figure 1}

North Central lowa field with high variability in soil characteristics, surface topography, and productive capacity: (a) soil organic matter, (b) surface slope, (c) soil sand fraction, and (d) corn grain yield.

(a)

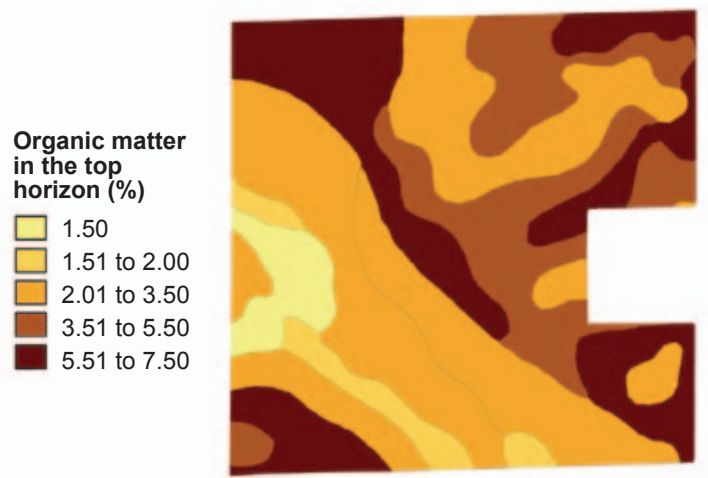

(c)

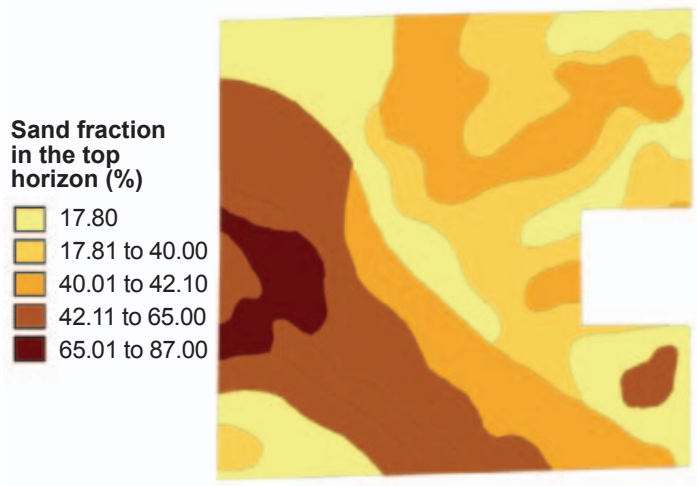

(b)

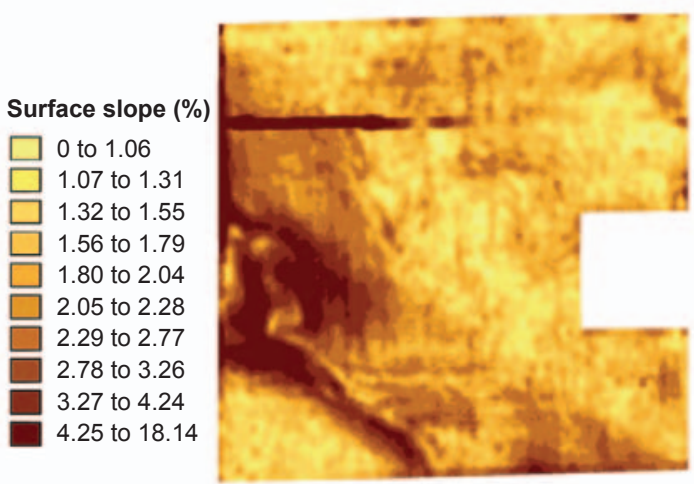

(d)

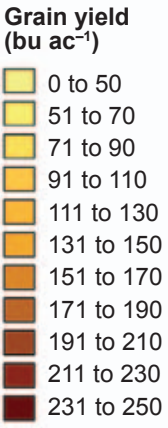

\section{Figure 2}

Select environmental performance characteristics: (a) USDA Natural Resources Conservation Service conservation planning metrics and (b) simulated nitrate $\left(\mathrm{NO}_{3}\right)$ leaching. $\mathrm{SCl}=$ soil conditioning index. $\mathrm{T}=$ tolerable soil loss.

(a)

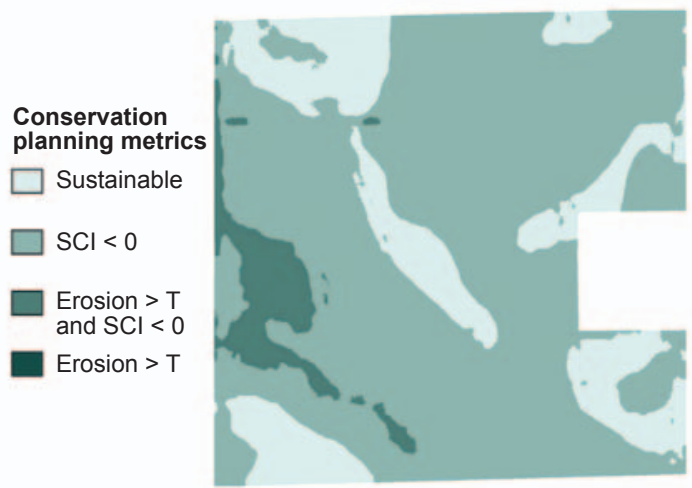

(b)

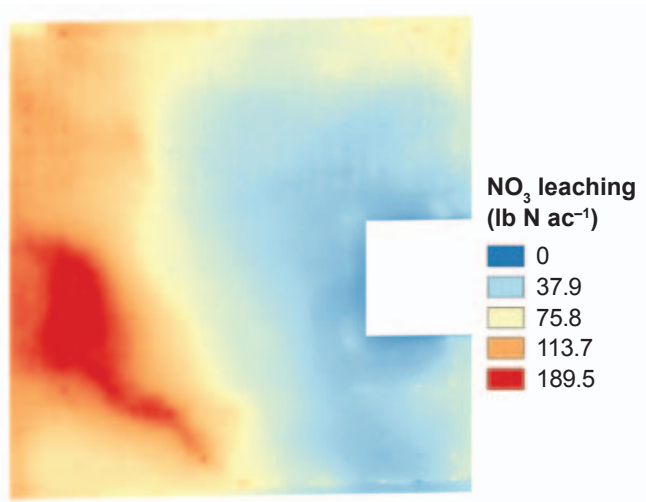

erally higher in areas of the field where yields are consistently lower. This result is both intuitive and potentially actionable. Specifically, this result is a single metric example of how focusing field management practices on increasing financial performance can improve environmental performance, i.e., focusing on making a better business decision can also result in a more environmentally sustainable decision.

\section{SUBFIELD PROFITABILITY}

Figure $3 \mathrm{a}$ shows the subfield profitability for the previously discussed field. The map in figure $3 \mathrm{a}$ uses 3 years of yield maps (2008 to 2010) to calibrate a crop growth model that is executed against 50 years of actual weather data for the field at a 10 $\mathrm{m}(33 \mathrm{ft})$ scale. The crop budget data used to calculate profitability are from the 2012 crop year for this field. The profit levels 


\section{Figure 3}

Subfield financial performance: (a) current management practices and (b) removing highly unprofitable areas from production.

(a)

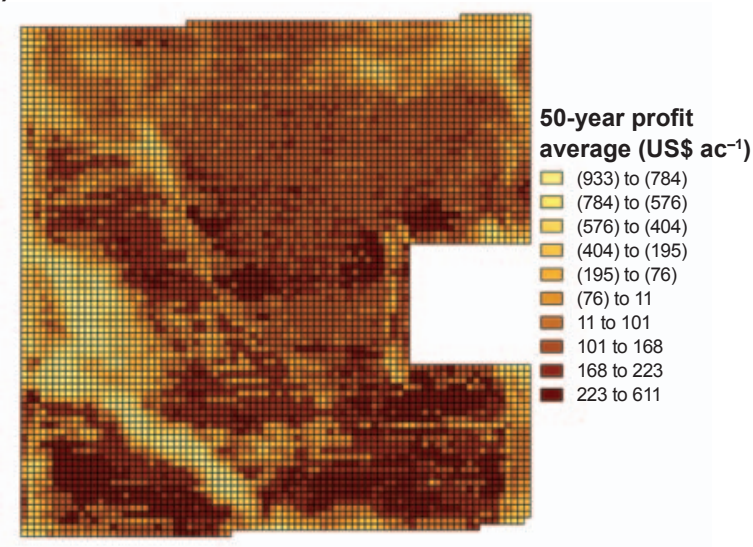

(b)

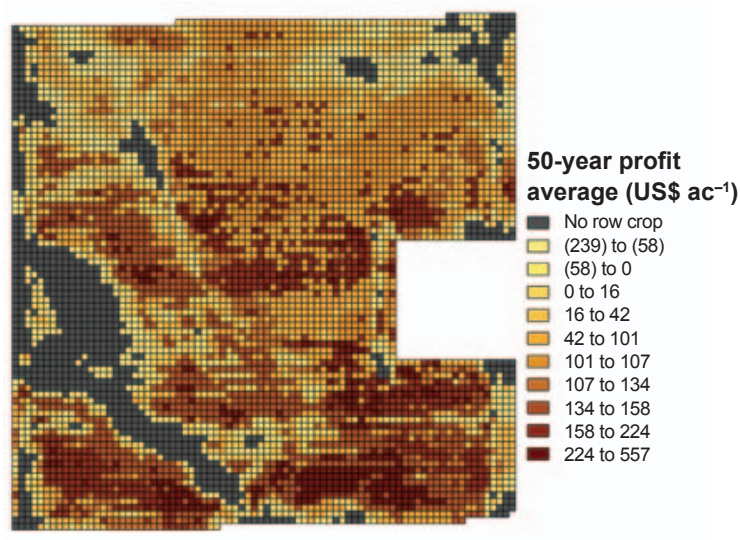

are very low or negative in the same areas of field where there is poor environmental performance, meaning that these areas are less effective at turning primary crop inputs into commodity outputs (figures $1 \mathrm{~d}$ and $2 \mathrm{~b})$. The concept of using readily available yield maps coupled to basic crop budgeting data to provide land managers with subfield profit maps is not new. Consultants and retailers have explored this idea as a mechanism to provide valueadding information to their customers since yield maps started becoming common in the 1990s. The challenge has been that taking a yield map and replacing the bushels per acre units with profit per acre does not provide actionable information. This is because production agriculture has focused almost exclusively on increasing yield as the single mechanism to increase profitability. Simply taking a yield map and displaying it as a profitability map provides the same information as was already available-increasing yield will increase profits.

As suggested by figures 1 and 2, there will often be areas of a field that always face yield potential limitations because of soil and surface topography characteristics. The challenge for a land manager is to improve profitability on parts of a field where yield is nearly always limited. More specifically, the land manager needs to improve ROI, or revenue per dollar of input cost for all areas of a field. This is a very important clarification because the land manager must frame the agronomic plan within a broader business-planning framework, i.e., a decision to apply $90 \mathrm{~kg}(200 \mathrm{lb})$ of nitrogen $(\mathrm{N})$ on an acre in the field can only be justified by having sufficient evidence of a return on that investment.

Figure $3 \mathrm{~b}$ applies this ROI businessplanning framework by executing a

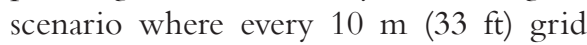
cell that has a 50 -year average financial loss of US $\$ 618 \mathrm{ha}^{-1}$ (US\$250 ac $\mathrm{ac}^{-1}$ ) or more is removed from the agronomic plan, i.e., no additional input investment beyond the cost of cash rent is allowed for those areas of the field. The result of this management change is that the field average profit is increased by US $\$ 72 \mathrm{ha}^{-1}$ (US\$29 $\mathrm{ac}^{-1}$ ). Comparing figures $2 \mathrm{~b}$ and $3 \mathrm{~b}$ finds that $\mathrm{N}$ losses from $\mathrm{NO}_{3}$ leaching can be decreased by $30 \%$ or more at the same time that field average profit is increased by over $60 \%$ from the base management scenario. This result is intuitive and useful, but it is also clear that the management plan proposed in figure $3 \mathrm{~b}$ is not operationally tenable in current production agriculture systems. However, the lessons here can be applied in a management planning framework that simultaneously increases financial and environmental performance. The proposed planning framework is called profit zones.

\section{PROFIT ZONE MANAGEMENT PLANNING}

The concept of profit zone management planning very simply prioritizes the business plan for a field and focuses on maximizing ROI for as much of the field as possible. Zones are developed based on historical precision field performance data. Zones are classified into three categories: (1) revenue zones, (2) expense-limited zones, and (3) no cost zones. Revenue zones represent the majority of most fields, and historical ROI performance in these zones suggests that investing in management practices that increase yield will provide positive profit returns. Expense-limited zones are the areas where primary row crop production can be profitable, but there are limitations to yield potential. An expenselimited zone will often present the best ROI by focusing on managing expenses to a target level. No cost zones present limited historical evidence of potential for positive ROI. The best business decision for a no cost zone is removing that area of a field from production and potentially finding an appropriate USDA conservation program or alternative crop to market. Splitting an individual field into multiple unique management zones does present operational challenges, and land managers have to make zone discretization decisions based on the ability for their operation to execute a zone-based management plan. The fundamental characteristic of a profit zone management plan is that the business decisions guide the planning process, and the agronomic plan is developed as a function of the business plan.

Figure 4 shows a simple profit zone management plan for the field discussed here. For a typical production year, this profit zone management plan can increase profit for this field by up to $50 \%$ while reducing $\mathrm{N}$ loss from $\mathrm{NO}_{3}$ leach- 
ing by $30 \%$ or more. Emerging precision agriculture technologies are decreasing the complexity of executing of a profit zone management plan. Variable rate technologies and multihybrid planters can, in some cases, implement a profit zone plan without changing current operational dynamics.

\section{VISION FOR THE FUTURE}

The purpose of this discussion is to provide a vision for improving the sustainability of production agriculture while simultaneously improving economic performance. We recognize that achieving the long-term goals for sustainability within our primary agricultural systems require actions well beyond the concepts discussed here, but we also believe that great progress can be made by focusing our current land management practices on simple, intuitive, and improved business decisions. Helping land managers improve the ROI in their systems will have significant positive environmental benefits. Emerging biomass markets and policy directives can support this vision not necessarily by competing with existing primary agricultural commodity production, but by providing viable alternatives for the areas of our fields that have limited ROI and poor environmental performance. Over time, we can collectively scale this same vision to subwatershed and watershed planning scales for continuous improvement toward longterm sustainability goals. In conclusion, we believe that profitability and environmental performance are often not competing in our production agriculture systems. We also believe that by using readily available precision agriculture data and technologies and focusing management planning on ROIbased business decisions, we can help land managers increase profitability and environmental performance simultaneously.

\section{REFERENCES}

Ebel, R., and D. Schimmelpfennig. 2011. The Information Age and Adoption of Precision Agriculture. Washington, DC: USDA Economic Research Service. http://www.ers.usda.gov/ amber-waves/2011-december/the-informationage.aspx\#.VCltaudmgzV.

Giltrap, D.L., C. Li, and S. Saggar. 2010. DNDC: A process-based model of greenhouse gas fluxes from agricultural soils. Agriculture, Ecosystems and Environment 136(3-4):292-300. http:// www.sciencedirect.com/science/article/pii/ S0167880909001996.

Muth D.J., D.S. McCorkle, J.B. Koch, and K.M. Bryden. 2012. Modeling sustainable agricultural residue removal at the subfield scale. Agronomy Journal 104(4):970-981.

\section{Figure 4}

Proposed profit zone based management plan.

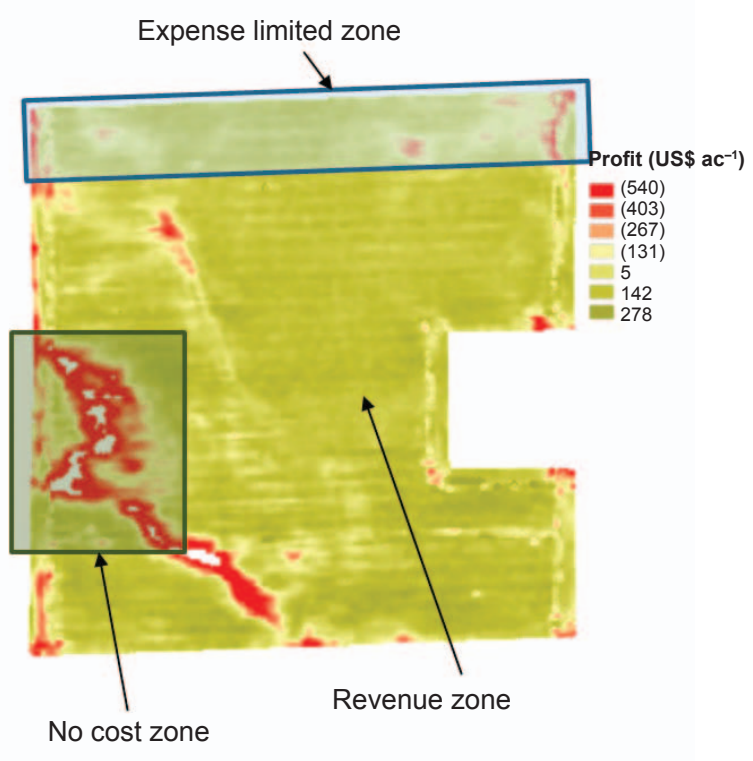

Pannell, D.J., G.R. Marshall, N. Barr, A Curtis, F, Vanclay, R. Wilkinson. 2006. Understanding and promoting adoption of conservation practices by rural landholders. Australian Journal of Experimental Agriculture 46(11):1407-1424. http://dx.doi.org/10.1071/EA05037.

USDA NRCS (Natural Resources Conservation Service). 2014a. Conservation Practices: Alphabetical Index. Washington, DC: USDA Natural Resources Conservation Service. http://www.nrcs.usda.gov/wps/ portal/nrcs/detailfull/national/technical/ references/?cid=nrcs143_026849.

USDA NRCS. 2014b. Description of SSURGO Database. Washington, DC: USDA Natural Resources Conservation Service. http://www. nrcs.usda.gov/wps/portal/nrcs/detail/national/ nedc/training/soil/?cid=nrcs142p2_053627. 